\title{
Atualidades/Actualities
}

\section{CONCEITUAÇÃO E HIERARQUIZAÇÃO DE ATIVIDADES DE PESQUISA*}

Nota-se, hoje $\mathrm{cm}$ dia, que os órgãos do Governo, financiadores de pesquisa, têm procurado organizar levantamertos da produção científica, classificando-as hieraquicamente dentro de campos, áreas, linhas de pesquisa entre outras. Entretanto, a classificaçăo de atividades e de trabalhos de investigação dentro de uma hierarquia de universos de interesses não tem sido processada com a uniformidade que seria desejável. Os conceitos classificatórios são geralmente vagos e, muitas vezes, conflitantes.

Esta desigualdade de critérios ou definiçôes traz, como consequiência, dificuldades para a classificação dos objetivos, dos interesses e das próprias atividades das diferentes instituições universitárias. Estas dificuldades também se fazem sentir quando da elaboração dos cadastros e na classificação da produtividade científica.

Desta forma, a Comissão de Biblioteca da Faculdade de Saúde Pública da USP tomou a iniciativa de estudar o assunto, pautando-se em colaboraçōes recebidas de docentes dos Departamentos que componeit: esta Faculdade, bem como de informações pessoais de outros pesquisadores.

São os seguintes os conceitos sobre atividades de pesquisa, propostos pela Faculdade de Saúde Pública, segundo hierarquia apresentada a seguir.

\section{Campo de Pesquisa}

E o conjunto de conhecimentos gerais cujos eventos são analisados em seus rela- cionamentos, por meio de raciocinio peculiar, no sentido de identificar e dimensionar causas, efeitos e conseqüências.

\section{Area de Pesquisa}

É um conjunto de conhecimentos específicos, metodologias e técricas relativos a determinados aspectos de um campo, podendo comportar sub-áreas.

\section{Linhas de Pesquisa}

Representam temas aglutinadores de estudos científicos, que se fundamentam em tradição investigativa, de onde se originam programas e projetos, cujos resultados se complementam.

\section{Programa de Pesquisa}

É uma proposta de investigaçăo que deriva de linhas de pesquisa, comportanto projetos afins, desenvolvidos concomitantemente ou sequiencialmente. Visa a acumulação de dados que possam ser adequadamente interpretados em termos de consecução de um objetivo geral comum.

\section{Projeto de Pesquisa}

Investigação, com início e final previstos, fundamentada em objetivos especificos visando a obter resultados de causa e efeito ou evidenciar fato novo, podendo ser parte ou năo de programas.

Como exemplo, podemos citar alguns dos projetos desenvolvidos na Faculdade de Saúde Pública com sua respectiva vinculação:

\footnotetext{
* Trabalho elaborado pela Comissão de Biblioteca e Documentação da Faculdade de Saúde Pública da USP - Av. Dr. Arnaldo, 715 - 01255 - São Paulo, SP - Brasil; constituida pelos seguintes Professores: Yaro Ribeiro Gandra (Pres:dente), Ruth Sandoval Marcondes, Victório Barbosa, Maria Helena Prado de Mello Jorge, Nelly Martins Ferreira Candeias, e Bibliotecária Maria Terezinha Dias de Andrade.
} 
Campo - Saúde Pública.

Area - Epidemiologia.

Linha - Doenças veiculadas por artrópodes.

Programa - Ecologia de Culicidae.

Projetos - Ciclo de atividades de Culicidae em floresta de planície litorânea.

Uma área pođerá ter mais que uma linha; uma linha mars que um programa; um programa um ou vários projetos. Um projeto poderá ser desenvolvido sem, necessariamente, estar ligado a um programa, mas deverá estar Tigado a uma linha.

O diagrama mostra o fluxo das atividades de pesquisa, desde campo até projeto e, conseqüentemente, à publicação do trabalho (Fig. 1).

Outros exemplos, também desenvolvidos na Faculdade de Saúde Pública, podem ser observados na Fig. 2, que apresenta um detalhamento do Diagrama (Fig. 1).

A presente proposta é, na realidade, uma tentativa para a hierarquização das atividades de pesquisa; propicia uma primeira oportunidade para se tentar disciplinar o assunto.

No sentido de aperfeiçoar sua proposta, a Comissão espera receber de outros especialistas sugestões e comentários.

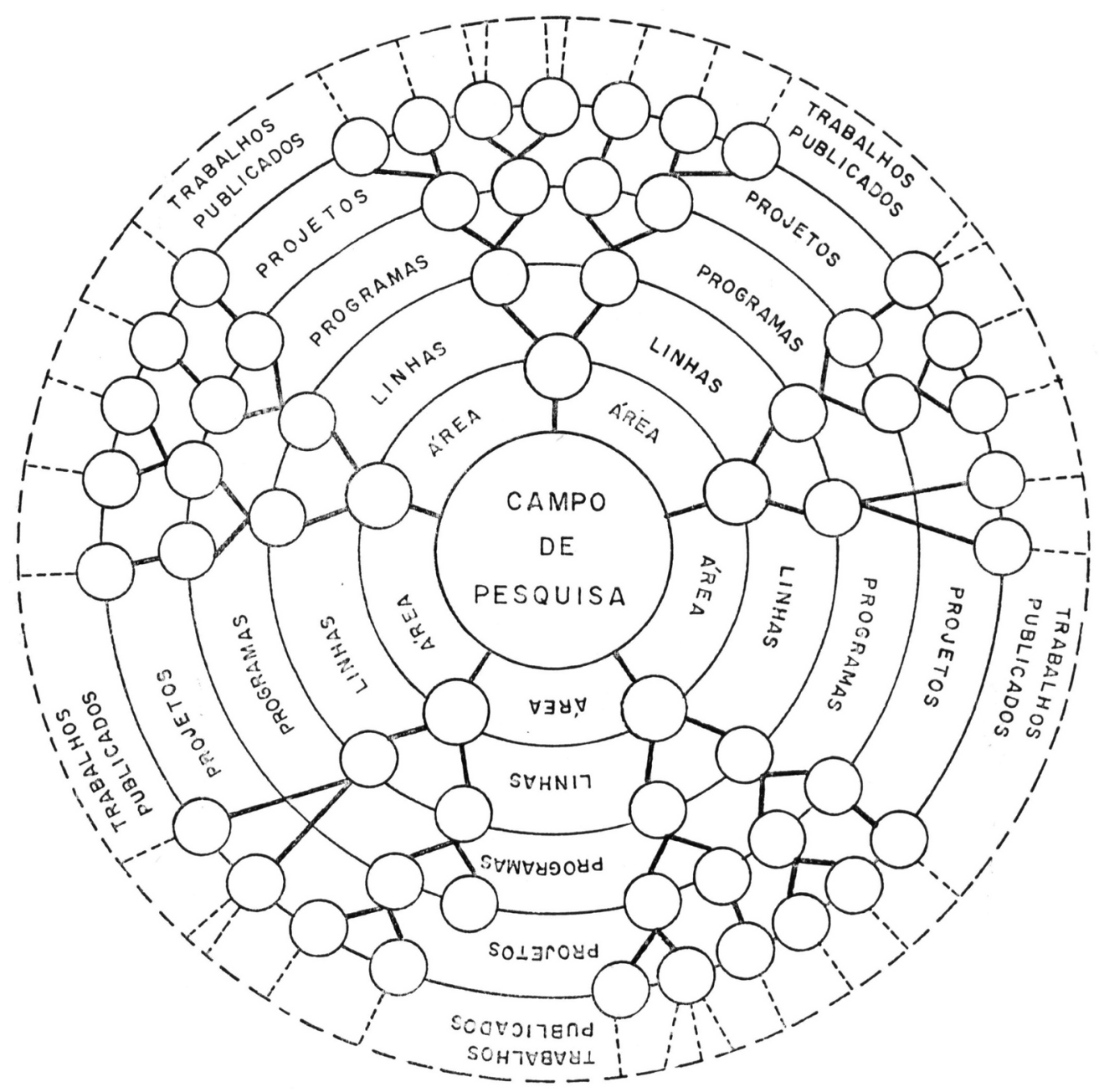

Fig. 1 - Diagrama de fluxo das atividades de pesquisa. 


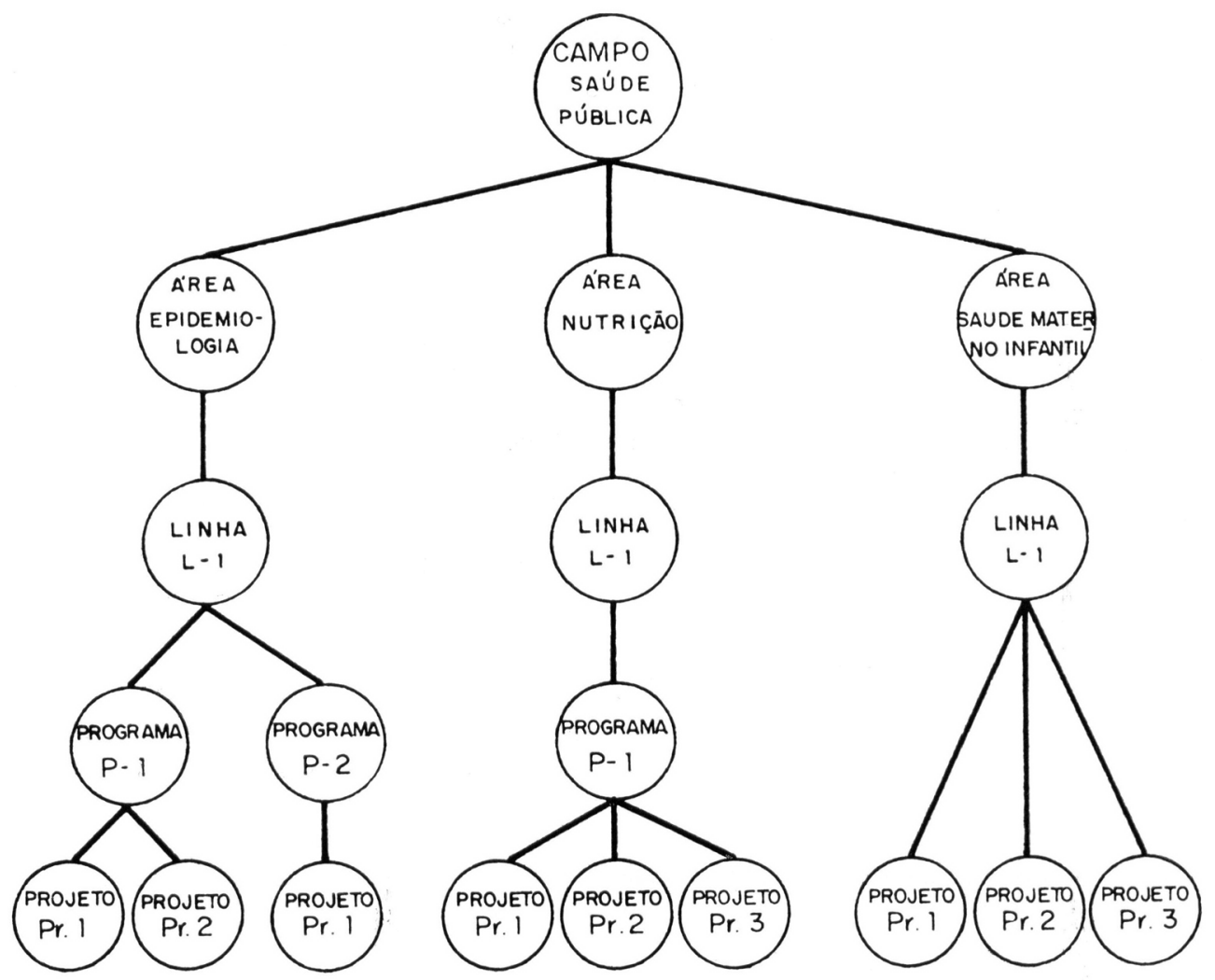

Fig. 2 - Detalhamento de parte do diagrama de atividades de pesquisa. Campo: SAƯDE PƯBLICA

Area: Epidemiologia

L-1: Epidemiologia das Doenças Veiculadas por Artrópodes

P-1: Ecologia dos Triatomíneos

Pr. 1: Pesquisas de ecótopos de Panstrongylus diasi no Estado de São Paulo.

Pr. 2: Estudo do comportamento do Panstrongylus megistus quanto à domiciliação, infecção e preferência alimentar no ecossistema da Serra do Mar.

P-2: Ecologia de Culicidae

Pr. 1: Ciclo de atividades de Culicidae em floresta da planície litorânea.

Área: Nutrigão

L-1: Epidemiologia das Deficiências Nrttricionais

P-1: Esti do do Desenvolvimento Integral do Pré-escolar

Pr. 1: Consumo alimentar de pré-escolares matriculados nos CEAPEs e de seus respectivos familiares.

Pr. 2: Avaliaçăo nutricional de pré-escolares - antropometria

Pr. 3: Avaliação do desenvolvimento biopsicomotor de pré-escolares dos CEAPEs

Area: Sauide Materno-Infantil

L-1: Sociologia da Reprodução Humana

Pr. 1: Classe social e incidéncia do aborto

Pr. 2: Risco gravídico e planejamento familiar

Pr. 3: Risco gravidico e saúde materna: uma abordagem sociológica. 